\title{
Factors predicting the oral health behaviors of the Iranian students in the
}

\section{District 1 Tehran, Iran.}

\section{Short running: oral health prediction}

\begin{abstract}
Mohammad Hossein Delshad ${ }^{*}$, Fatemeh Pourhaji ${ }^{2}$, Alireza Hidarnia ${ }^{2}$, Sedigheh Sadat Tavafian $^{2}$, Shamsodin Niknami

1. PhD of Health Education and Health Promotion, Shemiranat Health Network, Health Deputy Department, Shahid Beheshti University, Tehran, Iran. (Delshad@sbmu.ac.ir) and Department of Health Education and Health Promotion, Faculty of Medical Sciences, Tarbiat Modares University, Tehran, Iran and Public Health Department, Torbat Heydariyeh University of Medical Sciences, Torbat Heydariyeh, Iran. (h.delshad@modares.ac.ir), https://orcid.org/0000-0002-3512-9010

${ }^{2}$. Department of Health Education and Health Promotion, Faculty of Medical Sciences, Tarbiat Modares University, Tehran, Iran and Public Health Department, Torbat Heydariyeh University of Medical Sciences, Torbat Heydariyeh, Iran.
\end{abstract}

Fatemeh Pourhaji:https: / / orci d. org/ 0000- 0001- 6075- 5307

Alireza Hidarnia: htt ps: / / orci d. org/ 0000- 0003- 1534-4757

Sedigheh Sadat Tavafian:https: / / orci d. org/ 0000- 0003- 2842- 7172

Shamsodin Niknami:https: / / orci d. org/ 0000-0002- 8179-5719

Corresponding author:

*Dr.Mohammad Hossein Delshad

7th Floor, Bldg No.2 SBUMS, Arabi Ave, Daneshjoo Blvd, Velenjak, Tehran, Iran.

P.O. BOX: 19839-63113 Tel:+98 (21) 22211882 Fax: +98 (21) 22211882

Department of Health Education and Health Promotion, Faculty of Medical Sciences, Tarbiat Modares University, Tehran, Iran.

No 213, Department of Health Education and Health Promotion, Faculty of Medical Sciences, Tarbiat Modares University, Ghisa st., Jalae Ale Ahmd Ave, Tehran, Iran .

P.O. BOX: 14115-111 Tel:+98 (21) $82880000 \quad$ Fax: +98 (21) 82880000

E-mail:delshad@sbmu.ac.ir

\section{Acknowledgement}

The authors would like to thank all the participants who took part in the study. The authors also thank research deputy of Shahid Beheshti University for its financial support for this study (IR.SBMU.RETECH.REC.1396.625). 


\begin{abstract}
Aim: The purpose of this examination is determining predictors to oral health behaviors predict in Iranian students in district 1 Tehran based on the health belief model with added Commitment to plan construct.

Methods: This cross-sectional study was conducted on 351 four grade female students in the first district of Tehran, Iran in 2017. The random Multi-stage random cluster sampling method was used to recruit students. The inclusion criteria were being graded, four female students (aged 9-11 years), or Education at the fourth grade of one of the elementary schools studied in the first district of Tehran and, The health of the student from a physical and psychological of view. Logistic regression analysis was used to identify the variables that predict oral health behaviors.
\end{abstract}

Results: The total $31.8 \%$ of the students reported that they were brushing behavior less than twice a day and 55.2\% students claimed, use of dental floss behavior once a week or less than once a day. The results indicated that perceived self-efficacy $(\mathrm{OR}=1.46,95 \% \mathrm{CI}=0.57-3.78, \mathrm{P}<0.001)$, Commitment to plan $(\mathrm{OR}=1.13,95 \% \mathrm{CI}=1.04-1.23, \mathrm{P}<0.001)$ and Cues to action $(\mathrm{OR}=1.42,95 \% \mathrm{CI}=1.14-1.76, \mathrm{P}=0.002)$ were the significant predicting variables which is the key factor of brushing twice a day, and use of dental floss once a day or more $(\mathrm{OR}=1.02,95 \% \mathrm{CI}=0.23-3.53, \mathrm{P}=0.003)$.

Conclusion: This study has shown the effectiveness of the health belief model with added Commitment to plan construct to predict oral health behavior in female students. So, it seems that the model as a framework for designing training programs to improve students to improve oral health behavior can be used.

Key words: Oral Health; Students, Medical, Behavior, Iran. 


\section{Introduction}

Oral disorders are the most common health problems. Studies have shown that one of the commonest problems of early life is dental caries and oral diseases. Oral health is a part of the public health and essential to enhancing the quality of life ${ }^{1}$. Primarily based on the precept that prevention and training are the satisfactory manners of promoting oral health collectively, that extra prematurely preventive measures and interruption on disease evolution are established more effective might be the results ${ }^{2}$.

Distribution and severity of oral conditions vary in different components of the world and this is also real for specific geographic conditions within the equal country or area ${ }^{3}$. According to a countrywide oral health survey performed in 2012, indicated a high level of carries inside the primary dentition and the mean DMFT index become pronounced with 5.16/0.38 in 6-year-old children ${ }^{4}$.

Behavior elements and factors are received in early childhood and there is a strong mother or care. There is the fact that habits are at this age and caries in the first teeth ${ }^{2}$. Brushing and flossing are the very best methods to reduce the incidence of plaque ${ }^{5}$.

In addition, health education is considered a critical method for health promotion, now not best by the impact and voluntary wonderful adjustments within the individual's way of life and health habits; additionally, it improves familiar and community behavior, producing political behaviors that allow the development of new strategies to promote health and enhance the quality of lifestyles of the populace ${ }^{2,6}$. The implementation and effectiveness of educational preventive programs have become relevant because of the interception of risk factors for oral diseases, knowledge acquisition and consequently behavioral changes ${ }^{6}$.

In health education; the use of models and theories of health behavior to interventions is recommended because they can cause powerful health education programs. In fact, the models 
provide a framework for expertise on how people analyze and the way they behave and why humans behave as they offer ${ }^{7}$. The Health Belief model method is a comprehensive model that can be used for organizing educations. The HBM is a number of the first models which were advanced for regulating health-related behaviors ${ }^{8}$. On this version there are specific patterns of social-cognitive predictors can also appear (Figure 1) the construct of "Commitment to Plan of Action" from "Health Promotion Model Added to HBM model.

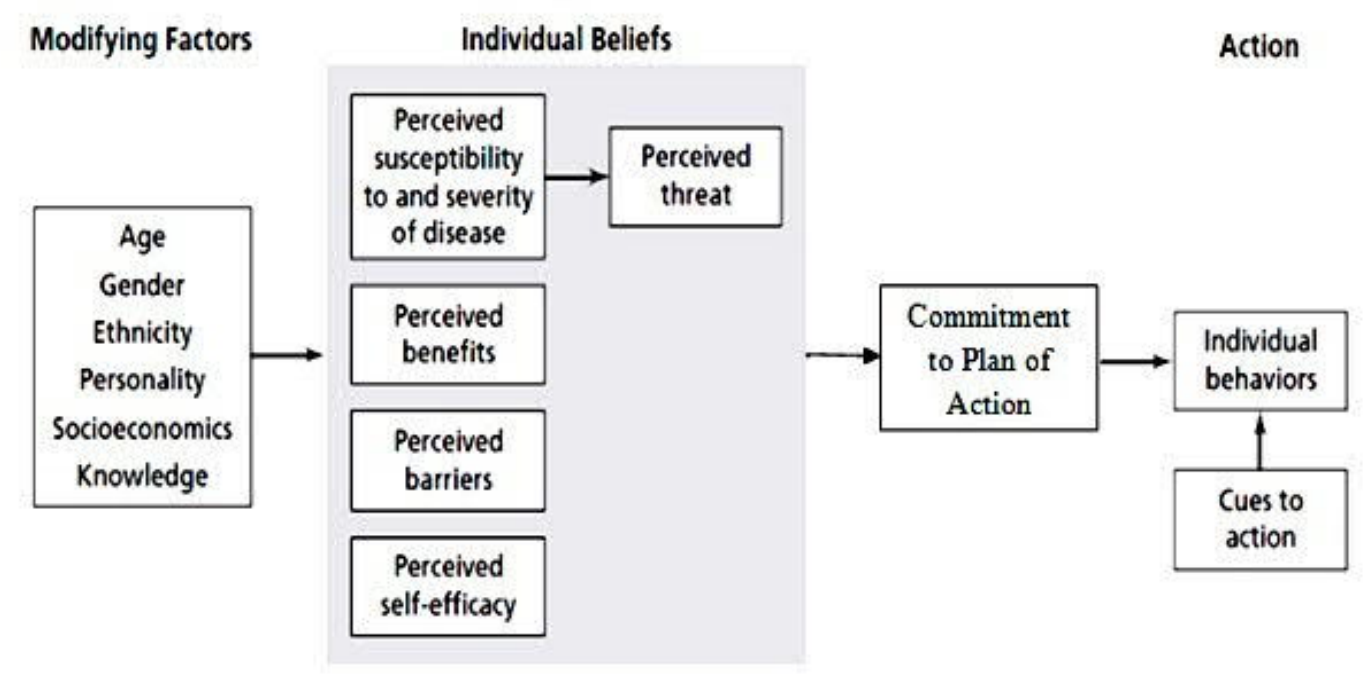

Figure 1. Flow Diagram of the expanded Health Belief model with the construct of "Commitment to Plan of Action" from "Health Promotion Model.

The model assumes that different factors, consisting of the perceived severity of health trouble, perceived benefits, and perceived barriers preventing people from assignment preventive behaviors, affect health related beliefs and behaviors ${ }^{9}$. The purpose of this examination is determining predictors to oral health behaviors example teeth brushing frequency, dental floss frequency and in Iranian students in district 1 Tehran based on the health belief model with added Commitment to plan construct. 


\section{Materials and methods}

Study design and participants

The study was cross-sectional, which was conducted on the grade four female students (9-11 years) of schools in the first district of Tehran on April 21, 2017, for 2 months. To obtain samples from among the 33,179 female students (grade four) studying in this Urban-rural, a Multi-stage random cluster sampling method was used.

In the first stage, out of 162 schools (145 urban schools and 17 rural schools), 10 schools [Urban schools ( $\mathrm{N}=6)$ and Rural schools $(\mathrm{N}=4)]$ were randomly selected.

In the second stage, From 351 students with it were random Based on the share of the population from each school and the number of schools and students in each school after declines 43 students, Assessed for eligibility ( $\mathrm{n}=308)$ (Table 1).

The inclusion criteria were being graded, four female students (aged 9-11 years), or Education at the fourth grade of one of the elementary schools studied in the first district of Tehran and, The health of the student from a physical and psychological point of view and the exclusion criterion was Student or parent's disagreement with the student company in the study and, the student determines the confrontation with their company in the study, the selected students were asked to respond to the study questionnaire.

The researcher was present while completing the questionnaire to help the students. The students were defined in the event that they to answer truly, this may assist the researchers to acquire the right information and improve knowledge (Figure 2). 


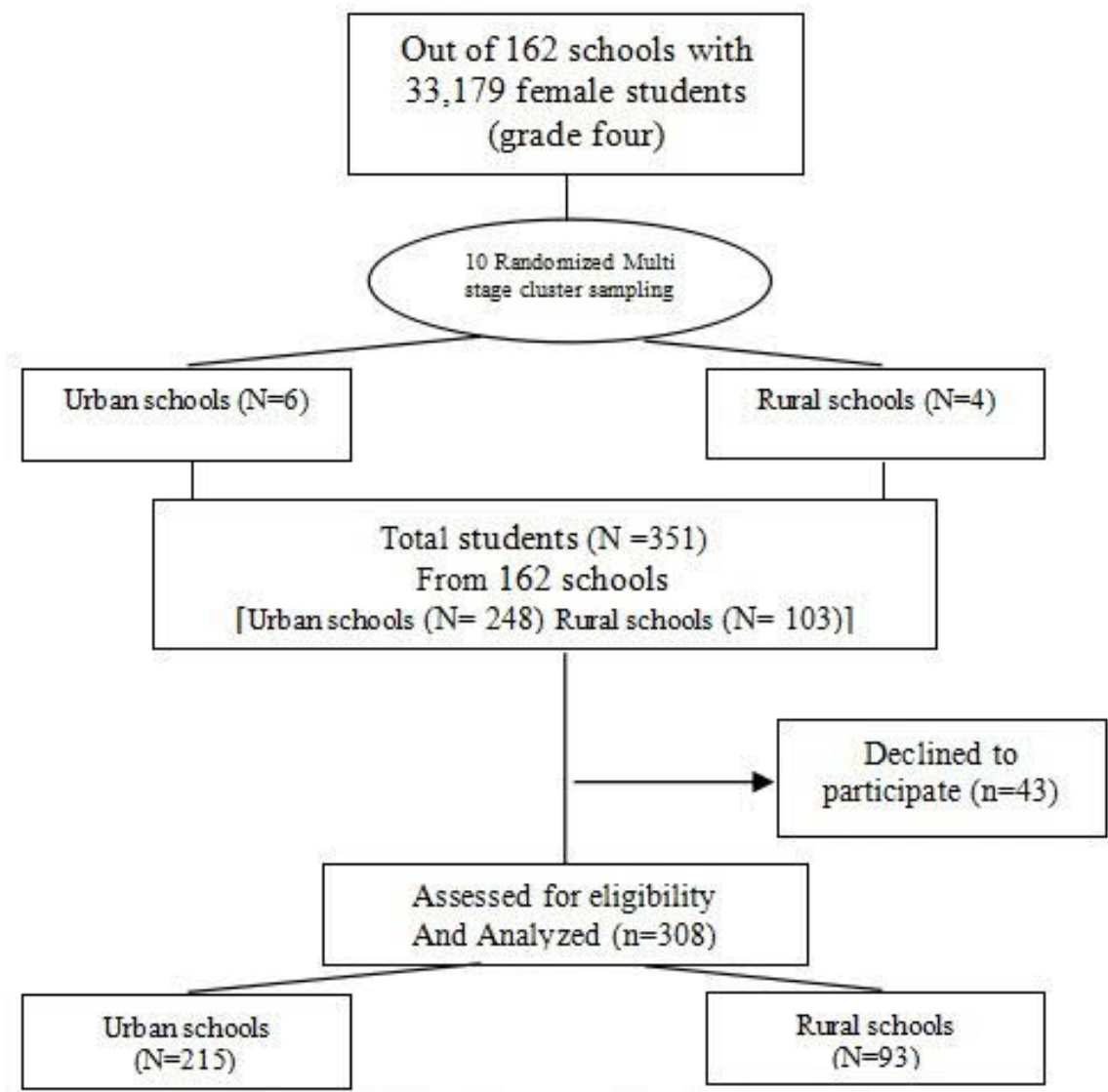

Figure 2. Flow diagram of student's recruitment.

\section{Results}

Totally, 308 four grade female students in the first district of Tehran took part in the study. The mean age of the subjects was $9.32 \pm 0.8$ years. The demographic variables of the study population are shown in Table 1,2 . About $31.8 \%$ of the students $(n=98)$ reported that they were brushing behavior less than twice a day, and 170 students $(55.2 \%)$ reported that they used once a week or after using dental floss behavior or less than once a day. While 210 students (68.2\%) reported that they brush behavior at least two twice a day, 138 students (44.8\%) reported that they were using dental floss behavior at least once a day. The results indicated that perceived self-efficacy $(\mathrm{OR}=1.46,95 \% \mathrm{CI}=0.57-3.78, \mathrm{P}<0.001)$, Commitment to plan $(\mathrm{OR}=1.13,95 \%$ $\mathrm{CI}=1.04-1.23, \mathrm{P}<0.001)$ and Cues to action $(\mathrm{OR}=1.42,95 \% \mathrm{CI}=1.14-1.76, \mathrm{P}=0.002)$ were the 
significant predicting variables which is the key factor of brushing twice a day, and use of dental floss once a day or more $(\mathrm{OR}=1.02,95 \% \mathrm{CI}=0.23-3.53, \mathrm{P}=0.003)$.

Table1. Demographic characteristics affecting of the students brushing behavior

\begin{tabular}{|c|c|c|}
\hline \multirow{4}{*}{ Demographic variables } & \multicolumn{2}{|c|}{ Brushing frequency } \\
\hline & less than twice a day & twice a day or more \\
\hline & $\mathbf{N}(\%)$ & $\mathbf{N}(\%)$ \\
\hline & $98(31.8)$ & $210(68.2)$ \\
\hline \multicolumn{3}{|c|}{ Father's educational level } \\
\hline Primary & $20(20.4)$ & $54(25.7)$ \\
\hline High school & $35(35.7)$ & $66(31.4)$ \\
\hline Higher educational & $43(43.9)$ & $90(42.9)$ \\
\hline \multicolumn{3}{|l|}{ P-value } \\
\hline \multicolumn{3}{|c|}{ Mother's educational level } \\
\hline Primary & $23(23.5)$ & $43(20.5)$ \\
\hline High school & $31(31.6)$ & $80(38.1)$ \\
\hline Higher educational & $44(44.9)$ & $87(41.4)$ \\
\hline \multicolumn{3}{|l|}{ P-value } \\
\hline \multicolumn{3}{|c|}{ Father's job } \\
\hline Private & $75(76.6)$ & $147(70)$ \\
\hline Employee & $23(23.4)$ & $63(30)$ \\
\hline P-value & & \\
\hline \multicolumn{3}{|c|}{ Mother's job } \\
\hline Un Employed & $50(51)$ & $110(52.4)$ \\
\hline Employed & $48(49)$ & $100(47.6)$ \\
\hline \multicolumn{3}{|l|}{ P-value } \\
\hline \multicolumn{3}{|c|}{ Income } \\
\hline Low & $10(10.2)$ & $16(7.6)$ \\
\hline Appropriate & $13(13.3)$ & $17(8.1)$ \\
\hline Well & $16(16.3)$ & $87(41.4)$ \\
\hline Excellent & $59(60.2)$ & $90(42.9)$ \\
\hline P-value & \multicolumn{2}{|c|}{0.04} \\
\hline
\end{tabular}

First stage

The recognition of effective demographic variables on oral health behaviors using Chi-square statistics. The related data are shown in Tables 1 and 2.

Based on the results given in Table 1, the education of mothers and Father's educational level respectively ( $\mathrm{p}=0.07 ; \mathrm{p}=0.03)$, the Father's job $(\mathrm{p}=0.09)$, and income $(\mathrm{P}=0.04)$ had a significant relationship with the students' brushing behavior. 
Table2. Demographic characteristics affecting of the students dental floss behavior

\begin{tabular}{|c|c|c|}
\hline \multirow{4}{*}{ Demographic variables } & \multicolumn{2}{|c|}{ Dental floss frequency } \\
\hline & once a week or less than once a day & once a day or more \\
\hline & $\mathbf{N}(\%)$ & $\mathbf{N}(\%)$ \\
\hline & $170(55.2)$ & $138(44.8)$ \\
\hline & \multicolumn{2}{|c|}{ Father's educational level } \\
\hline Primary & $38(22.4)$ & $34(24.6)$ \\
\hline High school & $65(38.2)$ & $48(34.8)$ \\
\hline Higher educational & $67(39.4)$ & $56(40.6)$ \\
\hline P-value & \multicolumn{2}{|c|}{0.03} \\
\hline & \multicolumn{2}{|c|}{ Mother's educational level } \\
\hline Primary & $33(19.4)$ & $33(23.9)$ \\
\hline High school & $67(39.4)$ & $47(34)$ \\
\hline Higher educational & $70(41.2)$ & $58(42.1)$ \\
\hline P-value & \multicolumn{2}{|c|}{0.5} \\
\hline & \multicolumn{2}{|c|}{ Father's job } \\
\hline Private & 164(96) & $89(64.5)$ \\
\hline Employee & $126(74)$ & $49(35.5)$ \\
\hline P-value & \multicolumn{2}{|c|}{0.04} \\
\hline & \multicolumn{2}{|c|}{ Mother's job } \\
\hline Un Employed & $115(67.6)$ & $73(52.9)$ \\
\hline Employed & $55(32.4)$ & $65(47.1)$ \\
\hline P-value & \multicolumn{2}{|c|}{0.8} \\
\hline & \multicolumn{2}{|c|}{ Income } \\
\hline Low & $30(17.7)$ & $24(17.4)$ \\
\hline Appropriate & $32(18.8)$ & $22(15.9)$ \\
\hline Well & $31(18.2)$ & $24(17.4)$ \\
\hline Excellent & $77(45.3)$ & $68(49.3)$ \\
\hline P-value & \multicolumn{2}{|c|}{0.2} \\
\hline
\end{tabular}

The children's use of dental floss behavior was significantly related to the Father's job ( $\mathrm{P}=$ 0.04), Father's educational level $(\mathrm{P}=0.03)$ (Table 2).

Table3. Factors predicting brushing behavior at least twice a day among of students

\begin{tabular}{|c|c|c|c|c|c|c|}
\hline $\begin{array}{c}\text { Brushing } \\
\text { behavior }\end{array}$ & $\boldsymbol{B}$ & Simple OR (95\% CI) & P-Value & $\boldsymbol{B}$ & Multiple OR (95\% CI) & P-Value \\
\hline $\begin{array}{c}\text { Mother's } \\
\text { educational level }\end{array}$ & & & 0.005 & & & 0.108 \\
\hline Primary & 0.16 & $1(0.40-2.51)$ & 1.32 & 0.19 & $1.14(0.54-2.65)$ & 0.26 \\
\hline High school & 0.47 & $1.60(0.92-2.78)$ & 0.63 & 0.38 & $1.46(0.57-3.78)$ & 0.02 \\
\hline $\begin{array}{c}\text { Higher } \\
\text { educational }\end{array}$ & 0.57 & $1.78(0.66-4.74)$ & 0.01 & 0.52 & $1.65(0.97-2.83)$ & 0.01 \\
\hline Income & & & 0.008 & & & 0.123 \\
\hline Low & 0.18 & $1.12(0.52-2.63)$ & 0.12 & 0.15 & $1.01(0.53-1.90)$ & 0.24 \\
\hline Appropriate & 0.23 & $1.24(1.14-1.38)$ & 0.18 & 0.20 & $1.13(0.53-2.64)$ & 0.18 \\
\hline Well & 0.28 & $1.36(0.47-3.68)$ & 0.02 & 0.25 & $1.18(0.41-2.59)$ & 0.01 \\
\hline Self-efficacy & 0.38 & $1.46(0.57-3.78)$ & $<0.001$ & 0.35 & $1.42(1.14-1.76)$ & 0.012 \\
\hline $\begin{array}{c}\text { Commitment to } \\
\text { plan }\end{array}$ & 0.18 & $1.13(1.04-1.23)$ & $<0.001$ & 0.15 & $1.02(0.36-2.52)$ & 0.014 \\
\hline Cues to action & 0.16 & $1.02(0.23-3.53)$ & 0.003 & 0.12 & $1(0.87-1.26)$ & 0.023 \\
\hline
\end{tabular}

$\mathrm{OR}=$ odds ratio, $\mathrm{CI}=$ confidence interval

\section{Second stage}

Using a logistic model for testing, the effect of six structures of HBM and demographic variables

having a significant relationship with oral health behaviors. Tables3, 4show the data used in the 
model. In order to find out the relationship between oral health behavior and independent variables, simple and multiple logistic regression analyses were carried out with five-six structures of HBM and demographic variables that were significant according to Tables 3, Mother's education $(\mathrm{P}=0.005)$, income $(\mathrm{P}=0.007)$, self efficacy, Commitment to plan ( $\mathrm{P}$ $<0.001)$ and Cues to action $(\mathrm{P}=0.003)$ predicted the students' behavior of Dental floss at least twice a day.

However, after adjustment, only perceived self-efficacy, Commitment to plan, Cues to action remained significant, so that one unit increase in perceived self efficacy increased the possibility of teeth Brushing behavior at least twice a day by 1.42 times, Commitment to plan by 1.02 times Cues to action by times.

Table4. Factors predicting use dental floss behavior at least once a day among of students

\begin{tabular}{|c|c|c|c|c|c|c|}
\hline $\begin{array}{c}\text { Dental floss } \\
\text { behavior }\end{array}$ & $\boldsymbol{B}$ & Simple OR ( $95 \%$ CI) & P-Value & $\boldsymbol{B}$ & Multiple OR (95\% CI) & P-Value \\
\hline Mother's job & & & 0.006 & & & 0.012 \\
\hline $\begin{array}{c}\text { Father's } \\
\text { educational level }\end{array}$ & & & 0.004 & & & 0.113 \\
\hline Primary & 0.18 & $1.20(0.54-2.70)$ & 0.61 & 1.19 & $0.78(0.37-1.69)$ & 0.23 \\
\hline High school & 0.47 & $1.60(0.92-2.78)$ & 0.01 & 0.28 & $1.36(0.47-2.68)$ & 0.01 \\
\hline $\begin{array}{c}\text { Higher } \\
\text { educational }\end{array}$ & 2.61 & $0.74(0.33-1.65)$ & 0.03 & 0.52 & $1.65(0.97-2.83)$ & 0.01 \\
\hline Income & & & 0.007 & & & 0.104 \\
\hline Low & -0.56 & $0.56(0.18-1.72)$ & 0.31 & 0.45 & $1.31(0.83-2.43)$ & 0.28 \\
\hline Appropriate & -0.034 & $0.96(0.31-3.01)$ & 0.95 & 0.20 & $1.15(0.55-2.66)$ & 0.23 \\
\hline Well & 0.13 & $1.14(0.35-3.65)$ & 0.81 & 0.21 & $1.12(0.35-2.53)$ & 0.01 \\
\hline Self-efficacy & 0.53 & $1.78(0.66-4.74)$ & $<0.001$ & 0.36 & $1.30(0.99-2.34)$ & 0.016 \\
\hline $\begin{array}{c}\text { Commitment to } \\
\text { plan }\end{array}$ & 0.18 & $1.13(1.043-1.23)$ & $<0.001$ & 0.15 & $0.89(0.38-1.54)$ & 0.21 \\
\hline Cues to action & 0.16 & $1.02(0.23-3.53)$ & 0.003 & 0.14 & $1.02(0.89-3.44)$ & 0.002 \\
\hline
\end{tabular}

The results showed that the students' use of dental floss behavior was significantly related to the mother's job $(\mathrm{P}=0.006)$, Father's educational level $(\mathrm{P}=0.004)$, income $(\mathrm{P}=0.007)$ perceived self efficacy ( $\mathrm{P}<0.001)$, Commitment to plan ( $\mathrm{P}<0.001)$, and Cues to action $(\mathrm{P}=0.003)$. When they were separately entered into the model (Table 4) Nevertheless, after adjustment, mother's job $(P=0.012)$ and self efficacy $(P=0.016)$ were found to be significantly related to the use of dental floss once a day or more. The increase of perceived self efficacy by one unit, the 
possibility of using dental floss at least once a day will increase by 1.30 times (OR $=1.30,95 \%$ $\mathrm{CI}=0.99-2.34, \mathrm{P}=0.016)$.

\section{Discussion}

The current survey was designed to investigate the predictors to oral health behaviors are expecting in Iranian students in district 1 Tehran based on the health belief model with added Commitment to plan construct Consistent with this examine findings, other research has mentioned a significant relationship between the education level of mother and father As Aggarwal study ${ }^{10}$ Contrary to the Pourhaji study, there was no significant relationship between education level and oral health behaviors the two groups ${ }^{1}$, a significant relationship between income, Father's job, dental floss behavior and brushing behavior in students same Phanthavong $\operatorname{study}^{11}$.

This study results indicated that perceived self-efficacy, Cues to action, and Commitment to plan were the significant predicting variables which is the key factor of teeth brushing and Brushing behavior at least twice a day, and use of dental floss and Brushing behavior once a day or more. According to the data, respectively the study carried out by Rahnama et al study ${ }^{12}$ and Hazavei study et $\mathrm{al}^{13}$ showed that self-efficacy, Cues to action had the highest percent of total variance observed in dental health behaviors.

But in there was a constrained correlation between oral health perceptions and elevated perceived benefits in solhi study $^{14}$. Maria et al study on the role of self-efficacy in dental patients' brushing and flossing, found that, barriers emerging, and self-efficacy significantly predicted brushing and flossing behaviors also ${ }^{15}$. 
However, it had no significant relation like the current study with perceived benefits and in contrast to current cues to action ${ }^{16}$. Maybe because of the age range of the participants who were in five-grade age and by gender.

Within the charkazi study, besides for perceived barriers (with negative correlation), all constructs of HBM were definitely associated with oral health behaviors. Self-efficacy was the most powerful predictor of oral health behavior ${ }^{17}$. The kasmaei findings recommend that perceived objective severity and perceived psychological barriers play an important position in adopting acceptable health behavior among younger young people ${ }^{18}$.

Moreover, according to the present study, numerous researches have revealed that commitment to plan has been as the best predictor variable for actual oral health behaviors ${ }^{19-20}$. Therefore, strategies for enhancing commitment to plan in practice, such as strengthening Selfextinguishing techniques, Enhance commitment, Pursuit of commitment and focus groups discussion could lead to more effective oral health behaviors programs for Iranian students and should be considered in future intervention ${ }^{21-22}$. These programs could propose that highly commitment to plan individuals exert greater efforts to empowering individuals to prevent them from returning to unhealthy behavior ${ }^{23}$. Pender stated that more commitment to plan could have a much impact on continuing health promotion behaviors ${ }^{24}$.

In this study, the variables of cues to action with a positive relationship were demonstrated to be significant predictors for oral health behaviors among the Iranian students. This finding is supported by many previous studies which found that Cues to action are stimuli that trigger appropriate health behaviors. Cues can be either internal, that is, the perception of bodily states, or external, that is, stimuli from the environment, such as interpersonal interactions or the mass $\operatorname{media}^{25-26}$. In the current study, there was also a relationship between Self-efficacy and oral 
health behaviors. Similar to the present study, Self-efficacy was the most predictive factors of oral health behaviors. These results are consistent with previous studies ${ }^{27-29}$.

\section{Limitations}

There are several limitations to this study. First, the statistics used on this evaluation were amassed via a cross-sectional design in addition to assessing oral health behaviors as self-report, in which humans typically might record the conduct better than the real amount. Furthermore, this observes changed into based totally on a comfort sample, so that it's locating of this study might not be generalized to all Iranian students groups to evaluate the real rate of behaviors and effective factor on them.

\section{Conclusions}

This study has shown the effectiveness of the health belief model with added Commitment to plan construct to predict oral health behavior in female students. So, it seems that the model as a framework for designing training programs to improve students to improve oral health behavior can be used. The finding of this study provides needed data assisting the development of modelbased behavioral prevention interventions to encourage student's oral health behavior.

\section{Acknowledgement}

The authors would like to thank all the participants who took part in the study. The authors also thank research deputy of Shahid Beheshti University for its financial support for this study (IR.SBMU.RETECH.REC.1396.625).

\section{Author contribution}

M H D, FP conducted whole study and had full access to all data for analysis.

SST, AH, MHD supervised the study and also she was involved in drafting the article 
SHN verified the data analysis. All authors confirmed the final version of the manuscript.

\section{Finance/Disclosure}

None declared.

\section{Conflict of Interest}

"The authors acclaimed that they have no rivaling interests".

\section{References}

1. Peyman N, Pourhaji F. The effects of educational program based on the health belief model on the oral health behaviors of elementary school students. 2015 .

2. Zeeberg C, Puello SdCP, Batista MJ, de Sousa MdLR. Effectiveness of a preventive oral health program in preschool children. Brazilian Journal of Oral Sciences. 2018;17:18063.

3. de Arruda Régis-Aranha L, dos Santos STC, Magalhães WOG, Pinto ABS, de Araújo Passos SM, Monteiro ÂX. Dental caries and visual acuity of students in a town in west amazon. Brazilian Journal of Oral Sciences. 2018:e18159-e.

4. Babaei A, Pakdaman A, Hessari H, Shamshiri AR. Oral health of 6-7 year-old children according to the Caries Assessment Spectrum and Treatment (CAST) index. BMC oral health. 2019;19(1):20.

5. Tiwari BS, Ankola AV, Jalihal S, Patil P, Sankeshwari RM, Kashyap BR. Effectiveness of different oral health education interventions in visually impaired school children. Special Care in Dentistry. 2019.

6. Fertman CI, Allensworth DD. Health promotion programs: from theory to practice: John Wiley \& Sons; 2016.

7. Pourhaji F, Vahedian Shahroodi M, Esmaily H. Effects of training program-based on Stage of change Model to promote Breast self-examination behavior. Scientific Journal of Hamadan Nursing \& Midwifery Faculty. 2013;21(4):59-68.

8. Almadi MA, Alghamdi F. The gap between knowledge and undergoing colorectal cancer screening using the Health Belief Model: A national survey. Saudi Journal of Gastroenterology. 2019;25(1):27. 
9. Rakhshanderou S, Hatami H, Delbarpoor-Ahmadi S. Predictors of Preventive Nutritional Behaviors of Cardiovascular Diseases among Women Referred to Community Health Centers of Shahid Beheshti University of Medical Sciences Based on the Health Belief Model. Community Health (Salāmat-i ijtimā̄i). 2019;6(1):61-9.

10. Aggarwal T, Goswami M, Dhillon JK. Assessment of Oral Health Educational Program on oral health status of visually impaired children in New Delhi. Special Care in Dentistry. 2019.

11. Phanthavong S, Nonaka D, Phonaphone T, Kanda K, Sombouaphan P, Wake N, et al. Oral health behavior of children and guardians' beliefs about children's dental caries in Vientiane, Lao People's Democratic Republic (Lao PDR). PloS one. 2019;14(1):e0211257.

12. Rahmati-Najarkolaei F, Rahnama P, Fesharaki MG, Yahaghi H, Yaghoubi M. Determinants of Dental Health Behaviors of Iranian Students Based on the Health Belief Model (HBM). Shiraz E-Medical Journal. 2016;17(7-8).

13. Hazavei SMM, SOHRABI VM, Moeini B, Soltanian AR, Rezaei L. Assessment of oral-dental health status: using Health Belief Model (HBM) in first grade guidance school students in Hamadan. 2012.

14. Solhi M, Zadeh DS, Seraj B, Zadeh SF. The application of the health belief model in oral health education. Iranian journal of public health. 2010;39(4):114.

15. Buglar ME, White KM, Robinson NG. The role of self-efficacy in dental patients' brushing and flossing: testing an extended Health Belief Model. Patient education and counseling. 2010;78(2):269-72.

16. Ramezankhani A, Mazaheri M, Dehdari T, Movahedi M. Relationship between health belief model constructs and DMFT among five-grade boy students in the primary school in Dezfool. Scientific Medical Journal/Majalleh Elmi Peseshki Daneshgahe Elome Pezeshki Ahwaz. 2011.

17. Reisi M, Javadzade SH, Shahnazi H, Sharifirad G, Charkazi A, Moodi M. Factors affecting cigarette smoking based on health-belief model structures in pre-university students in Isfahan, Iran. Journal of education and health promotion. $2014 ; 3$.

18. Kasmaei P, Shokravi FA, Hidarnia A, Hajizadeh E, Atrkar-Roushan Z, Shirazi KK, et al. Brushing behavior among young adolescents: does perceived severity matter. BMC Public Health. 2014;14(1):8. 
19. Vakili M, Rahaei Z, Nadrian H, YarMohammadi P. Determinants of oral health behaviors among high school students in Shahrekord, Iran based on Health Promotion Model. American Dental Hygienists' Association. $2011 ; 85(1): 39-48$.

20. Mehri A, Morowatisharifabad M. Utilizing the Health Promotion Model to predict oral health behaviors in the students of Islamic Azad University of Sabzevar(2008). Journal of Dental Medicine. 2009;22(1):81-7.

21. Ackley BJ, Ladwig GB, Msn R, Makic MBF, Martinez-Kratz M, Zanotti M. Nursing Diagnosis Handbook EBook: An Evidence-Based Guide to Planning Care: Mosby; 2019.

22. Arnold EC. Communication Strategies for Health Promotion and Disease Prevention. Interpersonal Relationships E-Book: Professional Communication Skills for Nurses. 2019:262.

23. Housman J, Odum M. Alters and Schiff Essential Concepts for Healthy Living: Jones \& Bartlett Publishers; 2019.

24. Srof BJ, Velsor-Friedrich B. Health promotion in adolescents: a review of Pender's health promotion model. Nursing Science Quarterly. 2006;19(4):366-73.

25. Feuerstein M, Labbé EE, Kuczmierczyk AR. Health psychology: A psychobiological perspective: Springer Science \& Business Media; 2013.

26. Champion VL, Skinner CS. The health belief model. Health behavior and health education: Theory, research, and practice. $2008 ; 4: 45-65$.

27. Albright DL, Godfrey K, McDaniel JT, Fletcher KL, Thomas KH, Bertram J, et al. Oral health among student veterans: Effects on mental and physical health. Journal of American College Health. 2019:1-8.

28. Berniyanti T, Bramantoro T, Palupi R, Wening GRS, Kusumo AD. Epidemiological investigation of caries level in 2nd and 3rd grader primary school student. Journal of International Oral Health. 2019;11(7):44.

29. Rachmawati YL, Maharani DA, Oho T. Cross-cultural Adaptation and Psychometric Properties of the Indonesia Version of the Self-efficacy Oral Health Questionnaire for Adolescents. International journal of paediatric dentistry. 2019. 